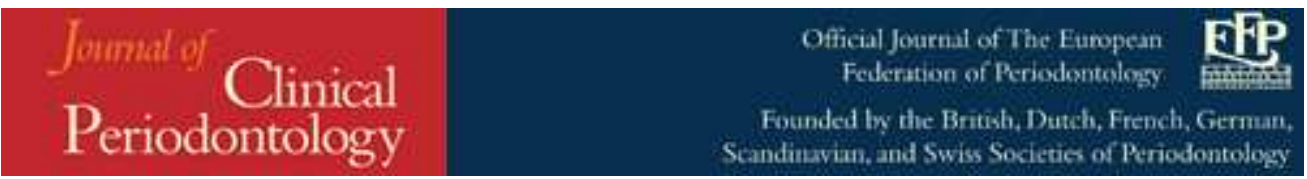

\title{
The interproximal clinical attachment level to classify gingival recessions and predict root coverage outcomes. An explorative and reliability study
}

\begin{tabular}{|c|c|}
\hline Journal: & Journal of Clinical Periodontology \\
\hline Manuscript ID: & CPE-10-10-2906.R1 \\
\hline Manuscript Type: & Original Article Clinical Periodontology \\
\hline $\begin{array}{r}\text { Date Submitted by the } \\
\text { Author: }\end{array}$ & $15-F e b-2011$ \\
\hline Complete List of Authors: & $\begin{array}{l}\text { Cairo, Francesco } \\
\text { Nieri, Michele; University of Florence, Periodontology } \\
\text { Cincinelli, Sandro; University of Florence, Periodontology } \\
\text { Mervelt, Jana; University of Florence, Periodontology } \\
\text { Pagliaro, Umberto; University of Florence, Department of } \\
\text { Periodontology }\end{array}$ \\
\hline Topic: & Treatment \\
\hline Keywords: & $\begin{array}{l}\text { Periodontal disease, gingival recession, diagnosis, classification, } \\
\text { aesthetics }\end{array}$ \\
\hline Main Methodology: & Clinical Trial \\
\hline
\end{tabular}

\section{SCHOLARONE Manuscripts}




\title{
The interproximal clinical attachment level to classify gingival recessions and predict root coverage outcomes. An explorative and reliability study
}

\author{
Francesco Cairo ${ }^{1}$, Michele Nieri ${ }^{1}$, Sandro Cincinelli ${ }^{1}$, Jana Mervelt ${ }^{1}$, Umberto \\ Pagliaro'. \\ ${ }^{1}$ Department of Periodontology, University of Florence - Florence, Italy.
}

Correspondence to: Dr. Francesco Cairo, - Via Mino Celsi 16, 53100- Siena

e-mail: cairofrancesco @ virgilio.it

Sources of funding: none.

Conflict of interest: The authors certify that there is no conflict of interest concerning the contents of the study. This study has been self-supported by the authors.

Key words: gingival recession, diagnosis, periodontal disease, classification, aesthetics, clinical attachment level, root coverage.

Running title: Interproximal CAL for gingival recessions 


\section{Clinical relevance}

Scientific rationale for the study

No information concerning the reliability of classifications of gingival recessions is currently available and there is no general consensus on the use of a specific system. In addition, the prediction of the gingival margin position following root coverage is a controversial issue.

\section{Principal findings}

Using the level of interproximal clinical attachment as identification criterion the proposed classification of gingival recessions showed an $\mathrm{ICC}=0.86$ (almost perfect agreement) among different examiners. Furthermore, the proposed classification was predictive of the final root coverage outcomes at the 6-month follow-up.

\section{Practical implications}

A classification system of gingival recessions based on the interproximal CAL may aid clinicians for a reliable categorization of defects and an effective prediction of treatment outcomes. 


\begin{abstract}
Background: The aims of this study were i) to test the reliability of a new classification system of gingival recessions using the level of interproximal clinical attachment as identification criterion ii) to explore the predictive value of the resulting classification system on the final root coverage outcomes.
\end{abstract}

\title{
Material and methods:
}

Patients showing at least one buccal gingival recession were recruited by one operator. Three recession types (RT) were identified. While class RT 1 included gingival recession with no loss of interproximal attachment, class RT 2 recession was associated with interproximal attachment loss less or equal to the buccal site and class RT 3 showed higher interproximal attachment loss than the buccal site. The classification was tested by two examiners blinded to the data collected by the other examiner. Intra-rater and inter-rater agreement was assessed. Furthermore, the 6-month root coverage outcomes of consecutively treated gingival recessions were retrospectively evaluated in order to explore the predictive value of the proposed classification on the final recession reduction.

\section{Results:}

The new classification system of gingival recessions was tested in a total of 116 gingival recessions (mean $3.2 \pm 1.2 \mathrm{~mm}$ ) in 25 patients. The Intra-class Correlation Coefficient (ICC) for inter-rater agreement was 0.86 showing an almost perfect agreement between examiners. The RT classification was predictive of the final recession reduction $(\mathrm{p}<0.0001)$ at the 6 -month follow-up in 109 treated gingival recessions.

Conclusions: The evaluation of interproximal clinical attachment level may be used to classify gingival recession defects and to predict the final root coverage outcomes. 


\section{INTRODUCTION}

Marginal tissue recession is defined as the displacement of the soft tissue margin apical to the cemento-enamel junction (CEJ) (American Academy of Periodontology 1996) and it is a frequent clinical feature in general population (Baelum et al. 1986; Yoneyama et al. 1988; Löe et al. 1992; Serino et al. 1994). Localized loss of attachment with gingival recession is frequently located at buccal tooth surfaces in patients with high standards of oral hygiene (Löe et al. 1992; Serino et al. 1994) and may be associated with mechanical factors such as traumatic tooth-brushing (Sangnes \& Gjermo 1976) and orthodontic movement (Joss-Vassalli et al. 2010), even if no definitive evidence is currently available (Rajapakse et al. 2007).

Some classifications of gingival recession are reported in the periodontal literature. In a classical article, soft tissue defects at mandibular incisors were divided into four classes: "narrow", "wide", "shallow" and "deep" (Sullivan \& Atkins 1968). Better root coverage outcomes following gingival graft procedure for narrow-shallow defects was reported (Sullivan \& Atkins 1968). Mlinek et al (1973) identified "shallow-narrow" defects as recession $<3 \mathrm{~mm}$, while "deep-wide" defects were recessions $>3 \mathrm{~mm}$. Miller (1985) proposed 4 classes of marginal tissue recessions based on both the level of gingival margin in respect with the muco-gingival junction (MGJ) and the underlying alveolar bone. In class I the recession did not extend to the MGJ, while in class II the gingival margin reached MGJ, both showing no loss of interproximal bone. In class III recession defect the gingival margin was located to or beyond the MGJ with interproximal bone loss and/or tooth malpositioning. Finally, class IV showed serious interproximal bone loss and/or severe tooth malpositioning. More recently, a compound index of recession was also proposed (Smith 1997) to assess both vertical and horizontal extent of the defect. The degree of horizontal component was expressed as a value ranging from 0 to 5 depending on the severity of CEJ exposure, while the vertical extent of recession was measured in millimeters using a periodontal probe on a 0-9 range (Smith 1997).

In the last two decades Miller' classification has become very popular and widely used. Recently, some criticisms to this classification were reported as the difficult differential diagnosis between Miller class I and II, the unclear procedures to ascertain the amount of soft/hard tissue loss in the interdental area to differentiate class III and IV and the unclear influence of tooth malpositiong (Pini Prato 2011). Furthermore, the possible need for a new classification system taking into account the progress made in the diagnosis and in the treatment of gingival recessions has been recently suggested (Mahajan 2010) in order to improve the simplicity of the diagnosis and the 
standardization of the clinical case. Finally, reliability and validity are central to determining the utility of any clinical parameters (Karras 1997) but information on the reliability of the published systems as the Miller's classification is currently not available and no general consensus on the use of a specific system exists.

Clinical variables involved in gingival recession might also be evaluated for anticipating a possible prognosis of root coverage outcomes. Miller (1985) hypothesized the feasibility of complete root coverage (CRC) using the free gingival graft procedure for class I and II, only a partial coverage for class III and not root coverage for class IV. More recently other possible prognostic factors as the amount of baseline recession (Clauser et al. 2003), the dimension of interdental papilla (Saletta et al. 2001), and the tooth type (Muller et al. 1998) were suggested as able to influence the final outcomes. On the other hand, the possible loss of interproximal attachment may be also able to predict the recession reduction (Rec Red).

The aims of this study were:

1. to test the reliability of a new classification system of gingival recessions using the level of interproximal clinical attachment as identification criterion.

2. to explore the predictive value of the resulting classification system on the final root coverage outcomes. 


\section{MATERIAL AND METHODS}

\section{Part 1: reliability study of a new classification of gingival recessions using the interproximal} CAL

Patients showing at least one buccal gingival recession were consecutively collected by the same periodontist (FC) in order to test the reliability of a new classification of gingival recession defects. All patients were recruited in the same private practice setting and signed a written informed consent in accordance with the Helsinki Declaration of 1975 as revised in 2000. Entry criteria were:

- presence of buccal recession defect at one or more teeth, irrespective to the amount of clinical attachment loss at the interproximal sites

- completion of casual-related therapy when necessary

- Full Mouth Plaque Score (FMPS) and Full Mouth Bleeding Score (FMBS) $<15 \%$ (4 sites/tooth)

- Detectable CEJ at the tooth with a recession

Exclusion criteria were:

- Tooth with prosthetic crown or restoration involving CEJ

- Presence of dental/root abrasion at the CEJ level

The following periodontal variables were recorded in a preliminary evaluation:

- $\quad$ REC at both buccal and interproximal sites.

- $\quad$ PD at both buccal and interproximal sites.

- $\mathrm{CAL}$ at both buccal and interproximal sites was then calculated.

Taking into account the desirable characteristics of a classification system (usefulness, exhaustiveness, disjointness and simplicity) suggested by Murphy (1997), the following classification of gingival recession was then identified based on the assessment of CAL at both buccal and interproximal sites.

- Recession Type 1 (RT1): Gingival recession with no loss of interproximal attachment. Interproximal CEJ was clinically not detectable at both mesial and distal aspect of the tooth (fig. 1a-1c). 
When both mesial and distal sites of the experimental tooth showed a CEJ with associated attachment loss, the interproximal site with highest loss of attachment was considered for the identification of the type of recession.

\section{Validation session}

Two periodontal examiners (JM-examiner n.1 and SC-examiner n.2) were recruited for the study. Both examiners were informed and trained on the use the proposed classification system and were blinded in respect with the evaluation of the first author (FC). All needed clarifications were provided before the study. Only one private office was involved in the study. Examiners twice evaluated each selected gingival recessions, independently and blindly. REC, PD and CAL were recorded for each defect. The examiners rated the recessions using the abovementioned classification system. There was no time restriction during the procedure.

\section{Sample size calculation}

The sample size to test the reliability of the new classification of gingival recessions was calculated using a minimal acceptance level of intra-class correlation coefficient (ICC) of 0.80 with an alternative hypothesis of $0.90,2$ operators, $\alpha=0.05$ and $\beta=0.01$ (Walter et al. 1998). With these parameters the required number of recessions was 114 . 


\section{Part 2: retrospective analysis to explore the predictive value of the resulting classification system on root coverage outcomes.}

Subsequently, the primary author (FC) selected periodontal chartings of patients treated with different mucogingival procedures, including gingival augmentation. All patients were consecutively treated by the same operator (FC) in a private practice setting from January 2006 to December 2008. Gingival recessions with or without interproximal loss of clinical attachment at baseline were enclosed in this retrospective analysis. In order to explore the predictive value of interproximal CAL on the 6-month root coverage outcomes, the following periodontal variables were then collected:

- the baseline depth of gingival recession (REC 0) at buccal site

- the baseline clinical attachment level (CAL B0) at buccal site

- the baseline clinical attachment level (CAL int) at interproximal sites.

- the final depth of gingival recession (REC 1) at buccal site

- the resulting recession reduction following therapy (Rec Red)

- the type of surgical procedure

The type of gingival recession (RT1, RT2 or RT 3) was then retrospectively assessed. 


\section{STATISTICAL ANALYSIS}

Descriptive statistics with mean \pm standard deviation [minimum; maximum] was performed.

The two-way random intra-class correlation coefficient (ICC) and 95\% confidence interval were used to assess the intra-rater and inter-rater agreement among the two periodontal examiners for the Recession Type (RT) and REC. In addition, inter-rater agreement (intra-class correlation coefficient (ICC) and 95\% confidence interval) were also assessed among the two periodontal examiners and the first author (FC).

These statistical analyses were performed with $\mathrm{R}$ software (version 2.9.2, The R Foundation for Statistical Computing, Package "irr").

A six-level nomenclature was used to assess the level of agreement (Landis \& Koch 1977):

- poor agreement: $<0.00$

- $\quad$ slight agreement: $0.00-0.20$

- fair agreement: 0.21-0.40

- moderate agreement: 0.41-0.60

- substantial agreement: 0.61-0.80

- almost perfect agreement: 0.81-1.00

In order to explore the predictive value of RT1 and RT2 class on recession reduction outcome a mixed model (REML) was used using the patient as random effect and REC 0 and RT as explicative variables. RT3 recessions were not included in this analysis since these defects were treated for gingival augmentation only and not for root coverage finality. 


\section{RESULTS}

A total of 25 patients (mean age $43.9 \pm 11.7$ years $[23 ; 66]$ ) were enrolled in order to test the reliability of a new classification of gingival recession. Sixteen patients were females. A total of 116 gingival recessions were evaluated. The mean buccal recession assessed by the primary author before the validation session was $3.2 \pm 1.2 \mathrm{~mm}[1 ; 6]$. Sixty-seven were located in the maxillary arch and 49 recessions were scored in the lower jaw. Twenty-two defects were found at the upper incisors, 30 at lower incisors, 25 at upper cuspids, 9 at lower cuspids, 18 at upper premolars, 9 at lower premolars, 2 at the upper molars and 1 at a lower molar. Based on the preliminary assessment of the first author (FC) a total of 32 defects (28\%) were considered as class RT1, 50 as class RT2 (43\%) and the 34 as class RT3 (29\%). Details of descriptive statistics are reported in table n. 1.

Intraclass Correlation Coefficient (ICC) and 95\% Confidence Interval between the two examiners (inter-rater agreement) was calculated for Recession Type (RT) and Recession depth (REC). It was $0.86(0.80 ; 0.90)$ for RT class and $0.88(0.83 ; 0.91)$ for REC showing an almost perfect agreement for both variables. The ICC for intra-rater agreement was 0.93 for the variable RT and ranged from 0.87 to 0.93 for the variable REC (table n. 2). Intra-class correlation coefficient (ICC) and $95 \%$ confidence interval for RT and Rec were also assessed among the two periodontal examiners and the primary author (FC). When comparing the examiner 1 with the primary author the ICC was 0.90 $(0.86 ; 0.93)$ for RT and $0.86(0.80 ; 0.90)$ for REC. When comparing the examiner 2 with the primary author the ICC was $0.88(0.83 ; 0.91)$ for RT and $0.89(0.85 ; 0.93)$ for REC.

A different group of 66 patients (36 females and 30 males) treated with different mucogingival procedures were enrolled in the study in order to explore the predictive value of RT class on the final root coverage outcomes. The mean age was $37.6 \pm 11.4$ years [21;62]; 19 patients were smokers. The treatment outcomes of 133 gingival recessions were then evaluated: 5\% were at central upper incisors, $10 \%$ at lateral upper incisors, $30 \%$ at upper cuspids, $15 \%$ at upper premolars, $3 \%$ at upper molars, $19 \%$ at lower incisors, $10 \%$ at lower cuspids, $7 \%$ at lower premolars and $1 \%$ at

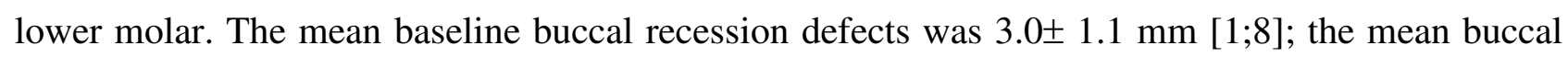
loss of attachment was $4.1 \pm 1.3 \mathrm{~mm} \mathrm{[2;9];} \mathrm{the} \mathrm{mean} \mathrm{loss} \mathrm{of} \mathrm{interproximal} \mathrm{attachment} \mathrm{was} 1.6 \pm 2.5$ $\mathrm{mm}[0 ; 8]$. A total of 35 recessions were treated using the coronally advanced flap for multiple recessions (CAF multi), 19 recessions with coronally advanced flap for single recession (CAF), 28 recessions with $\mathrm{CAF}$ plus connective tissue graft $(\mathrm{CAF}+\mathrm{CTG}), 36$ recessions with the free gingival graft (FGG), 8 recessions with double papilla flap with connective tissue graft (DPF+CTG), 3 
recessions with CAF plus enamel matrix derivative (CAF+EMD), 2 recessions with the laterally positioned flap (LPF) and 2 recessions with FGG+CAF.

In table 3 details of descriptive statistics concerning treated gingival recessions enclosed in the explorative study for the predictive value of RT class are reported. The mixed model (table 4) was limited to 109 out of the 133 selected defects, corresponding to classes RT 1 and RT2 recessions only. Data for the residual 24 RT3 recessions treated with gingival augmentation procedure were excluded from the analysis since the treatment had no root coverage finality. The results of the analysis showed that RT class is a strong predictor $(\mathrm{p}<0.0001)$ of the final recession reduction (table 4). When considering a similar baseline REC 0 for RT1 and RT2 classes, RT1 showed a higher mean Rec Red $(0.57 \mathrm{~mm})$ compared with RT2 (CI95\%: from 0.31 to $0.84 \mathrm{~mm}$ ). 


\section{DISCUSSION}

The treatment of gingival recession is a common query in patients with high standard of oral hygiene. Different surgical procedures are associated with the CRC (Cairo et al. 2008) and final improvement of aesthetics (Cairo et al. 2009; Kerner et al. 2009; Cairo et al. 2010). The classification of the type of gingival recession is a very important issue in clinical trials dealing with root coverage procedures. In the last two decades Miller's classification has become a very popular approach in identifying soft tissue recessions (Miller 1985). Recently, the use of Miller's classification was reviewed and the difficult inclusion for some recessions in a specific class was outlined (Mahajan 2010; Pini Prato 2011). The development of a new classification system of gingival recession on the basis of the characteristics of suitable taxonomy and validated by reliability study for its use in clinical practice was then advocated (Pini Prato 2011).

The first aim of this study was to test the reliability of a new classification system for gingival recessions using the level of interproximal CAL as identification criterion. This approach is based on the observation that the CAL is extensively used to evaluate periodontal conditions (Papapanou $\&$ Lindhe 2008). The interproximal CAL may also be considered as a reliable tool to indirectly assess the presence of bone loss (Papapanou \& Wennström 1989). In this classification, gingival recessions without loss of interproximal attachment were considered as RT 1 defects, representing defects most likely associated with traumatic tooth-brushing only in healthy periodontal tissue. Gingival recessions associated with the presence of clinical attachment loss were divided into classes RT 2 and RT 3, thus clustering defects associated with periodontal disease. While RT 2 defects showed an amount of interproximal attachment less or equal to the buccal site (i.e. a gingival recession associated with horizontal bone lone loss), RT 3 recessions showed higher interproximal attachment loss than the buccal site (i.e. a gingival recession associated with an interproximal infrabony defect). This differential diagnosis may help clinician in selecting the proper treatment.

The reliability of this system is confirmed by the intra-rater agreement (ICC $=0.86)$ with an almost perfect agreement between the two examiners. Similar outcomes were obtained in assessing intrarater reliability and comparing the two examiners with the primary author. A possible explanation for these findings may be related with the fact that only defects with a CEJ showing no tooth abrasion in the cervical area were recruited, leading to a simple CAL assessment. Furthermore, only patients with minimal gingival inflammation (FMPS and FMBS $<15 \%$ ) were enrolled in this study, thus reducing the possible apical displacement of probe tip during the measurements (Armitage et 
al. 1977). This condition may have improved the reliability of the measurements. It must be kept also into account that no assessment of keratinized tissue (KT) surrounding the gingival recession was performed in this classification. Although the baseline KT amount might be useful in the selection of the surgical procedure, the influence of KT on root coverage outcomes is still a controversial topic (Cairo et al. 2008). On the other hand, if the final target of the procedure is the CRC along with an increase of KT, the combination between CAF plus CTG was associated with better clinical outcomes (Cairo et al. 2008).

The prediction of the amount of recession reduction following root coverage is another important issue in current practice. Recently, a method of predetermination of the final position of the gingival margin using the height of the interdental papilla was suggested (Zucchelli et al. 2010). This procedure was able to predict in $71 \%$ of treated cases the position of the gingival margin 3 months after surgery (Zucchelli et al. 2010). The second aim of our study was to explore the predictive value of RT class on the final root coverage outcomes. The results of the analysis showed that this variable is a strong predictor $(\mathrm{p}<0.0001)$ of the final Rec Red after different surgical procedures. It should be hypothesized that the level of interproximal CAL may be considered an ideal stop of the possible coronal shift of gingival margin and gain in clinical attachment at the buccal site following surgery. This may be associated with stability and blood supply provided by interproximal soft tissue to the buccal flap/graft during the healing process. When considering a similar baseline REC 0 for RT1 and RT2 classes, RT1 showed a higher mean Rec Red $(0.57 \mathrm{~mm})$ compared with RT2 class: this finding supports the importance of baseline interproximal CAL for the prognosis of gingival recession treatment. Interestingly, 8 out of 33 RT 2 defects (24\%) reported CRC after different root coverage procedures. Although it is suggested that only a partial root coverage can be anticipated for gingival recession with interdental bone loss (Miller 1985), this finding supports initial observations from a randomized study reporting the feasibility of CRC for multiple recessions with interproximal bone loss and treated with the tunnel technique plus CTG (Aroca et al. 2010). However, further well-designed trials are needed to explore the predictability of CRC in relation with specific surgical procedures for the treatment of single RT2 recession defects. On the other hand, RT3 recessions were not included in this explorative analysis since these defects were treated with FGG for gingival augmentation only and not for root coverage finality. However a slight coronal improvement of the gingival margin was detected at the 6-month follow-up (mean Rec Red 0.4 \pm 0.9 ) probably associated with a creeping attachment following FGG (Matter 1980). Based on this observation, it might be hypothesized that interdental soft/hard tissue reconstruction with gain in clinical attachment seems to be mandatory before considering predictable root coverage procedure at the buccal site. 
Limits of this explorative study may be related with the selection of gingival recessions associated with a completely detectable CEJ only in assessing the reliability of the new classification system of gingival recession. On the other hand, a recent study proposing a classification of dental defects in areas with gingival recession reported that CEJ may be not identifiable in some cases (Pini-Prato et al. 2010). In this condition, a different fixed point for CAL assessment, such as incisal margin, is needed. However, a possible combination of both classifications for assessing soft and hard tissue defects may be recommended. Furthermore it must be kept into account that the assessment of the predictive value of RT class on the final root coverage outcomes is a retrospective analysis. Further well-designed prospective randomized studies are recommended to better explore the influence of interproximal CAL along with other potential prognostic factors as patient related (e.g. smoking habits), tooth/site related (e.g. the baseline recession depth, the presence of root abrasion) and technique related (the use connective tissue graft, the type of flap design) on the final root coverage outcomes.

In conclusion, this study suggests that the evaluation of interproximal CAL may be used to classify gingival recession defects and to predict the final root coverage outcomes. 


\section{References}

American Academy of Periodontology (1996). Consensus report on Mucogingival Therapy. Proceedings of the World Workshop in Periodontics. Annals of Periodontology 1:702-706

Armitage, G.C., Svanberg, G.K., Löe, H. (1977) Microscopic evaluation of clinical measurements of connective tissue attachment levels. Journal of Clinical Periodontology 4:173-190

Aroca, S., Keglevich, T., Nikolidakis, D., Gera, I., Nagy, K., Azzi, R., Etienne, D. (2010) Treatment of class III multiple gingival recessions: a randomized-clinical trial. Journal of Clinical Periodontology 37:88-97.

Baelum, V., Fejerskov, O. \& Karring, T. (1986) Oral hygiene, gingivitis and periodontal breakdown in adult Tanzanians. Journal of Periodontal Research 21:221-232

Cairo, F., Pagliaro, U. \& Nieri, M. (2008) Treatment of gingival recession with Coronally Advanced Flap procedures. A systematic review. Journal of Clinical Periodontology 35 (Supp 8), 136-162.

Cairo, F., Rotundo, R., Miller, P.D. \& Pini Prato, G.P. (2009) Root coverage esthetic score: a system to evaluate the esthetic outcome of the treatment of gingival recession through evaluation of clinical cases. Journal of Periodontology 80, 705-710.

Cairo, F., Nieri, M., Cattabriga, M., Cortellini, P., De Paoli, S., De Sanctis, M., Fonzar, A., Francetti, L., Merli, M., Rasperini, G., Silvestri, M., Trombelli, L., Zucchelli, G., Pini-Prato, GP. (2010) Root coverage esthetic score after treatment of gingival recession: an interrater agreement multicenter study. Journal of Periodontology 81:1752-1758.

Clauser, C., Nieri, M., Franceschi, D., Pagliaro, U., Pini-Prato, G. (2003) Evidence-based mucogingival therapy. Part 2: Ordinary and individual patient data meta-analyses of surgical treatment of recession using complete root coverage as the outcome variable. Journal of Periodontology 74:741-756.

Landis, J.R. \& Koch, G.G. (1977) The measurement of observer agreement for categorical data. Biometrics 33, 159-174. 
Löe, H., Anerud, A. \& Boysen, H. (1992) The natural history of periodontal disease in man: prevalence, severity, and extent of gingival recession. Journal of Periodontology 63:489-495.

Joss-Vassalli, I., Grebenstein, C., Topouzelis, N., Sculean, A., Katsaros, C. Orthodontic therapy and gingival recession: a systematic review. Orthodontics \& Craniofacial Research 2010, 13:127-141.

Karras D.J. (1997) Statistical methodology: II. Reliability and validity assessment in study design, part B. Academic Emergency Medicine 4, 144-149

Kerner, S., Katsahian, S., Sarfati, A., Korngold, S., Jakmakjian, S., Tavernier, B., Valet, F. \& Bouchard P. (2009) A comparison of methods of aesthetic assessment in root coverage procedures. Journal of Clinical Periodontology 36:80-87.

Mahajan A. (2010) Mahajan's modification of Miller's classification for gingival recession. Dental Hypotheses 1, 45-50

Matter J. (1980) Creeping attachment of free gingival grafts. A five-year follow-up study. Journal of Periodontology 51:681-685.

Miller, P.D. (1985) A classification of marginal tissue recession. International Journal of Periodontics and Restorative Dentistry 5:8-13

Mlinek, A., Smukler, H. \& Buchner, A. (1973) The use of free gingival grafts for the coverage of denuded roots. Journal of Periodontology 44:248-254

Müller, H.P., Eger, T., Schorb, A. (1998) Gingival dimensions after root coverage with free connective tissue grafts. Journal of Clinical Periodontology 25:424-430.

Murphy E.A. (1997) The Logic of Medicine. II Edition, p. 119-136, Baltimore and London. The Johns Hopkins University Press

Papapanou, P.N. \& Wennström, J.L. (1989) Radiographic and clinical assessments of destructive periodontal disease. Journal of Clinical Periodontology 16:609-612.

Papapanou, P.N. \& Lindhe, J . (2008) Epidemiology of Periodontal Diseases - In: Clinical Periodontology and Implant Therapy. Lindhe, J., Lang N.P. \& Karring, T. Editors. Fifth edition, p. 129-179, Oxford. Blackwell Munksgaard 
Pini-Prato, G., Franceschi, D., Cairo, F., Nieri, M. \& Rotundo R. (2010) Classification of dental surface defects in areas of gingival recession. Journal of Periodontology 81:885-890.

Pini-Prato, G. (2011) The Miller classification of gingival recession: limits and drawbacks. Journal of Clinical Periodontology 38:243-245.

Rajapakse, P.S., McCracken, G.I., Gwynnett, E., Steen, N.D., Guentsch, A. \& Heasman, P.A. (2007). Does tooth brushing influence the development and progression of non-inflammatory gingival recession? A systematic review. Journal of Clinical Periodontology 34:1046-1061

Saletta, D., Pini Prato, G., Pagliaro, U., Baldi, C., Mauri, M., Nieri, M. (2001) Coronally advanced flap procedure: is the interdental papilla a prognostic factor for root coverage? Journal Periodontology 72:760-766.

Sangnes, G. \& Gjermo, P. (1976) Prevalence of oral soft and hard tissue lesions related to mechanical tooth cleaning procedures. Community Dentistry and Oral Epidemiology 4:77-83.

Serino, G. Wennström, J.L., Lindhe, J. \& Eneroth, L. (1994) The prevalence and distribution of gingival recession in subjects with a high standard of oral hygiene. Journal of Clinical Periodontology 21:57-63.

Smith, R.G. (1997). Gingival recession. Reappraisal of an enigmatic condition and a new index for monitoring. Journal of Clinical Periodontology 24:201-205.

Sullivan, H.C. \& Atkins, J.H. (1968) Free autogenous gingival grafts. 3. Utilization of grafts in the treatment of gingival recession. Periodontics 6:152-160.

Walter, S.D., Eliasziw, M. \& Donner, A. (1998) Sample size and optimal design for reliability studies. Statistics in Medicine 17:101-110.

Yoneyama, T., Okamoto, H., Lindhe, J., Socransky, S.S. \& Haffajee A.D. (1988) Probing depth, attachment loss and gingival recession. Findings from a clinical examination in Ushiku, Japan. Journal of Clinical Periodontology 15:581-591.

Zucchelli, G., Mele, M., Stefanini, M., Mazzotti, C., Mounssif, I., Marzadori, M., Montebugnoli, L. (2010) Predetermination of root coverage. Journal of Periodontology 81:1019-1026. 


\section{TABLES}

\section{Table1:}

Reliability study of the new classification of gingival recession: distribution of Recession Type (RT) at different teeth

\begin{tabular}{|l|c|c|c|c|c|c|c|c|c|}
\hline Class & $\begin{array}{l}\text { Upper } \\
\text { Incisors }\end{array}$ & $\begin{array}{l}\text { Upper } \\
\text { cuspids }\end{array}$ & $\begin{array}{l}\text { Upper } \\
\text { Premolars }\end{array}$ & $\begin{array}{l}\text { Upper } \\
\text { Molars }\end{array}$ & $\begin{array}{l}\text { Lower } \\
\text { incisors }\end{array}$ & $\begin{array}{l}\text { Lower } \\
\text { Cuspids }\end{array}$ & $\begin{array}{l}\text { Lower } \\
\text { Premolars }\end{array}$ & $\begin{array}{l}\text { Lower } \\
\text { Molars }\end{array}$ & Total \\
\hline RT1 & 1 & 14 & 3 & - & 6 & 4 & 3 & 1 & 32 \\
\hline RT2 & 14 & 5 & 12 & - & 15 & 2 & 2 & - & 50 \\
\hline RT3 & 7 & 6 & 3 & 2 & 9 & 3 & 4 & - & 34 \\
\hline & $\mathbf{2 2}$ & $\mathbf{2 5}$ & $\mathbf{1 8}$ & $\mathbf{2}$ & $\mathbf{3 0}$ & $\mathbf{9}$ & $\mathbf{9}$ & $\mathbf{1}$ & $\mathbf{1 1 6}$ \\
\hline
\end{tabular}




\section{Table 2}

Reliability study of the new classification of gingival recession: intra-rater agreement for the examiner n.1 (JM) and the examiner n.2 (SC) for Recession Type (RT) and Recession depth (REC).

\begin{tabular}{|l|c|c|}
\hline Variable & Examiner n.1: ICC (95\% CI) & Examiner n.2: ICC (95\% CI) \\
\hline RT class & $0.93(0.90 ; 0.95)$ & $0.93(0.90 ; 0.95)$ \\
\hline REC & $0.93(0.89 ; 0.95)$ & $0.87(0.82 ; 0.91)$ \\
\hline
\end{tabular}

Legend: Intraclass Correlation Coefficient (ICC); 95\% Confidence Interval (95\% CI) 


\section{Table 3:}

Descriptive statistics of defects analyzed in the explorative analysis for the predictive value of the proposed classification on the final recession reduction. The defects were retrospectively categorized according gingival recession types.

\begin{tabular}{|l|c|c|c|}
\hline Variable & RT 1 (n=76) & RT 2 $(\mathbf{n = 3 3})$ & RT 3 (n=24) \\
\hline REC 0 $(\mathrm{mm})$ & $2.8 \pm 1.0$ & $3.2 \pm 1.4$ & $3.5 \pm 0.5$ \\
\hline CAL buccal $(\mathrm{mm})$ & $3.9 \pm 1.0$ & $4.3 \pm 1.5$ & $4.6 \pm 0.7$ \\
\hline CAL interproximal (mm) & $0 \pm 0$ & $1.6 \pm 0.6$ & $6.6 \pm 0.8$ \\
\hline Rec Red (mm) & $2.5 \pm 0.9$ & $2.2 \pm 0.8$ & $0.4 \pm 0.9$ \\
\hline Rec 1 (mm) & $0.3 \pm 0.5$ & $1.1 \pm 0.9$ & $3.3 \pm 0.6$ \\
\hline Sites with CRC & $56(74 \%)$ & $8(24 \%)$ & $0(0 \%)$ \\
\hline
\end{tabular}

Legend: RT 1= Recession Type 1; RT 2= Recession Type 2; RT 3= Recession Type 3; REC 0= Buccal recession at the baseline; CAL buccal= buccal clinical attachment level; CAL interproximal $=$ interproximal clinical attachment level; Rec Red= Recession reduction; Rec 1= recession at the 6-month follow-up; Sites with CRC= number of defects with complete root coverage at the 6-month follow-up. 


\section{Table 4:}

Mixed model (REML) using patient as random effect to explore the predictive value of Rec 0, RT1 and $\mathrm{RT} 2$ on recession reduction outcome. $\mathrm{N}=109 ; \mathrm{R}^{2}=0.83$.

\begin{tabular}{|l|c|c|c|}
\hline & Estimate & Standard error & p-value \\
\hline Intercept & 0.40 & 0.17 & \\
\hline Rec B & 0.65 & 0.05 & $<0.0001$ \\
\hline Class [RT1] & 0.29 & 0.07 & $<0.0001$ \\
\hline
\end{tabular}

Legend: Rec $\mathrm{B}=$ baseline depth of gingival recession at both buccal site; Class= Recession Type 


\section{Figures Legend}

Fig. 1a: A buccal gingival recession at the upper left canine

Fig. 1b: The level of buccal clinical attachment was $3 \mathrm{~mm}$

Fig. 1c: The interproximal CEJ is not detectable: the final diagnosis is RT1

Fig. 2a: A buccal gingival recession at the upper left canine

Fig. 2b: The level of buccal clinical attachment was $4 \mathrm{~mm}$

Fig. 2c: The level of interproximal clinical attachment was $3 \mathrm{~mm}$ : the final diagnosis is RT2

Fig. 3a: A buccal gingival recession at the upper left lateral incisor

Fig. 3b: The level of buccal clinical attachment was $6 \mathrm{~mm}$

Fig. 3c: The level of interproximal clinical attachment was $8 \mathrm{~mm}$ : the final diagnosis is RT3 


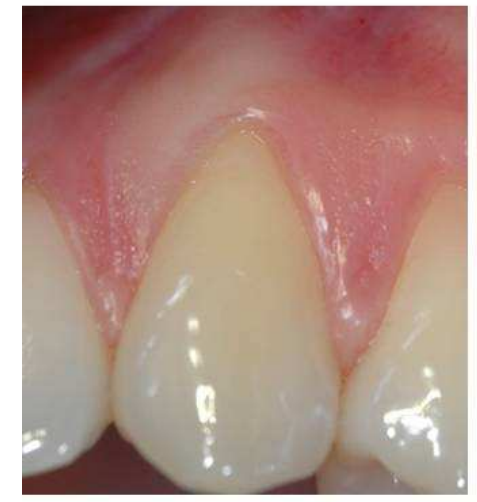

Fig. 1a

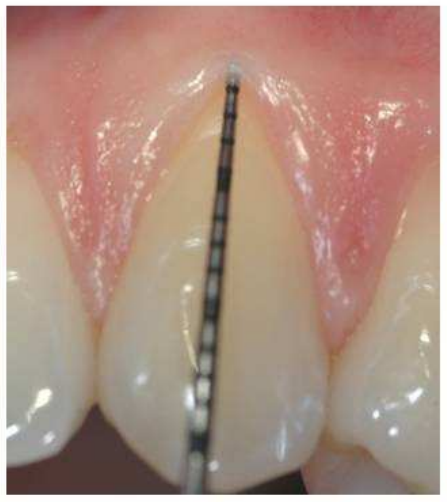

Fig. 1b

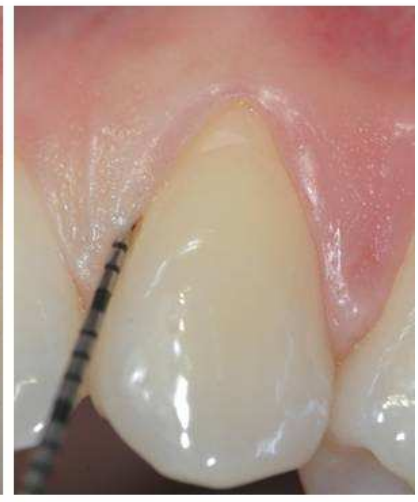

Fig. 1c

Fig. 1a: A buccal gingival recession at the upper left canine

Fig. 1b: The level of buccal clinical attachment was $3 \mathrm{~mm}$

Fig. 1c: The interproximal CEJ is not detectable: the final diagnosis is RT1

$254 \times 190 \mathrm{~mm}(96 \times 96 \mathrm{DPI})$ 


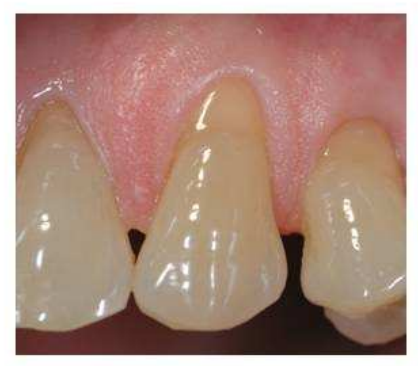

Fig. 2a

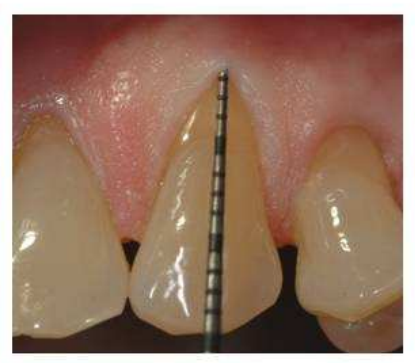

Fig. 2b

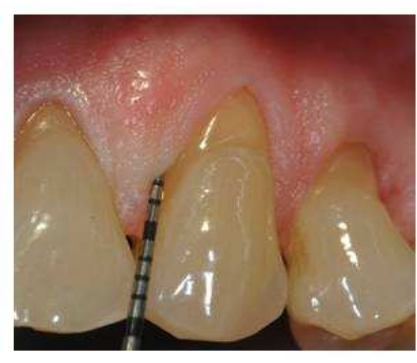

Fig. 2c

Fig. 2a: A buccal gingival recession at the upper left canine Fig. 2b: The level of buccal clinical attachment was $4 \mathrm{~mm}$ Fig. 2c: The level of interproximal clinical attachment was $3 \mathrm{~mm}$ : the final diagnosis is RT2 $254 \times 190 \mathrm{~mm}(96 \times 96 \mathrm{DPI})$ 


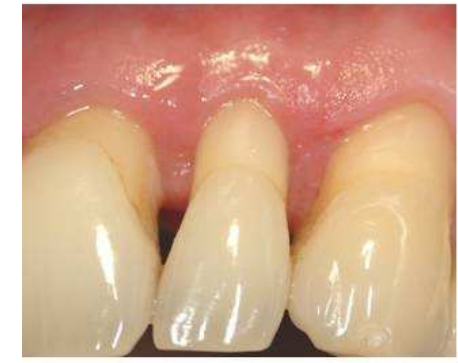

Fig. 3a

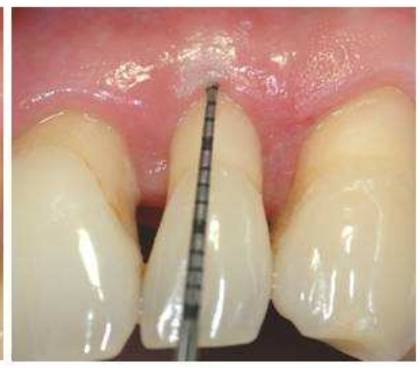

Fig. 3b

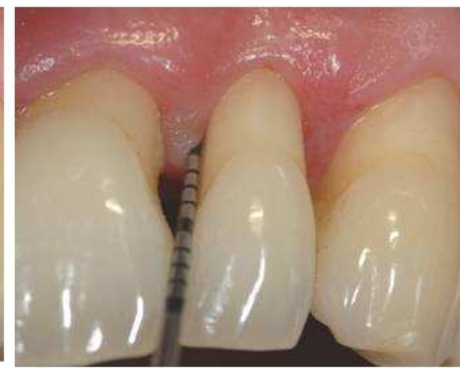

Fig. 3c

Fig. 3a: A buccal gingival recession at the upper left lateral incisor Fig. 3b: The level of buccal clinical attachment was $6 \mathrm{~mm}$ Fig. 3c: The level of interproximal clinical attachment was $8 \mathrm{~mm}$ : the final diagnosis is RT3 $254 \times 190 \mathrm{~mm}(96 \times 96 \mathrm{DPI})$ 